\title{
Determinantes do Lance Vencedor em Leilões de Petróleo e Gás: Avaliando o Caso Brasileiro*
}

\author{
Rodrigo Leandro de Moura ${ }^{\dagger}$, Maurício Canêdo-Pinheiro ${ }^{\ddagger}$, Fernando \\ Daitx $^{\S}$
}

Conteúdo: 1. Introdução; 2. Legislação; 3. Teoria dos Leilões e a Indústria de Petróleo e Gás;

4. Metodologia; 5. Base de Dados e Estatísticas Descritivas; 6. Resultados;

7. Conclusões.

Palavras-chave: Leilões de Petróleo e Gás; Econometria de Leilões; Assimetria de Informação.

Códigos JEL: D44, C29, D82.

Este artigo usa a metodologia de Rezende (2008) parainvestigar os determinantes do lance vencedor em leilões de bloco de petróleo e gás no Brasil. Há indicação de que os efeitos da "maldição do vencedor"de fato se manifestam nas estratégias adotadas pelas empresas nesses leilões. Também são encontradas evidências de que a presença da Petrobras tem efeito positivo no valor dos lances ofertados. Além disso, consórcios entre empresas aparentemente não têm motivaçã o anticompetitiva. Por fim, não há indícios da existência de sinergias entre os blocos. Desse modo, embora haja espaço para melhora no desenho das licitações promovidas no Brasil, o desempenho dos leilões selados de primeiro preço (sem a possibilidade de lances por pacotes de blocos) não tende a ser muito inferior às alternativas possíveis.

This paper follows Rezende (2008) to investigate the determinants of bidding strategy in the Brazilian oil and gas auctions. The results indicate that strategies adopted by participants are affected by the "winner's curse". We also found evidence that the presence of Petrobras has a positive effect

\footnotetext{
* Agradecemos à Adriana Hernandez-Perez e ao Allan Vasconcellos que foram os responsáveis por uma versão preliminar da base de dados utilizada; aos participantes do $39^{\circ}$ Encontro Nacional de Economia (Anpec), do V Encontro de Políticas Públicas e Crescimento Econômico CAEN-EPGE, do Seminário do IBRE e a dois pareceristas anônimos por seus comentários e sugestões. Qualquer erro eventual é nossa responsabilidade.

${ }^{\dagger}$ Pesquisador da Economia Aplicada do IBRE/FGV e Professor de Economia da EBEF/FGV. E-mail: rodrigo. leandro@fgv . br .

$\ddagger$ Pesquisador da Economia Aplicada do IBRE/FGV e Professor de Economia da EBEF/FGV. E-mail: mauricio.pinheiro@fgv.br.

$\S$ Graduando de Economia da EBEF/FGV. E-mail: fernandodait@fgvmail .br
} 
on winning bids. Furthermore, joint bidding is compatible with competition. Finally, there is no evidence of synergies between blocks. Thus, although there is room for improvements, results of the first-price sealed auction (without the possibility of bidding for blocks packages) are not much better than possible alternatives.

\section{INTRODUÇÃO}

Leilões de blocos de petróleo e gás têm despertado muito interesse da literatura. Este interesse está associado tanto à importância e aos valores envolvidos nesses leilões, quanto às características particulares dos objetos leiloados. Ao contrário de leilões em que os objetos têm valores privados e independentes, os blocos têm o mesmo valor (desconhecido) para todas as empresas, sendo somente revelado após a efetiva exploração da reserva de petróleo. Em leilões desse tipo (de valores comuns), é usual a manifestação do fenômeno da "maldição do vencedor": se uma empresa arremata um bloco por valores muito superiores aos demais lances, provavelmente trata-se de má notícia, pois significa um erro de avaliação do potencial da área. Ademais, os valores dos blocos são potencialmente interdependentes entre si, por conta de sinergias existentes na produção de petróleo em áreas próximas umas das outras. Por fim, a incerteza geológica faz com que determinados agentes estejam mais bem informados que outros quanto ao potencial do bloco objeto de leilão.

Entretanto, se o caso norte-americano tem sido bastante explorado pela literatura [ver Cramton (2007) para referências], como o mercado brasileiro foi aberto à competição há menos de duas décadas, somente recentemente a experiência brasileira tem recebido maior atenção. Nesse sentido, têm sido investigados desde aspectos relacionados à participação de empresas estrangeiras [Costa e Lopes (2008)] até temas associados à presença e ao impacto de assimetrias entre as empresas que participam do leilão, em particular entre a Petrobras e as demais [Brasil et alii (2008), Matoso (2009), Brasil e Postali (2010) e Matoso e Rezende (2011)]. ${ }^{1}$

Este artigo se insere justamente nesse debate, na medida em que investiga os determinantes do lance vencedor em leilões de bloco de petróleo e gás no Brasil. Alguns artigos já se debruçaram sobre o mesmo tema. Entretanto, ou se utilizaram de base de dados menos detalhadas [Motta e Ribeiro (2010)] ou de métodos econométricos pouco adequados ao contexto de leilões de valores comuns [Matoso (2009) e Hernandez-Perez (2011b)]. ${ }^{2}$ Nesse sentido, é utilizada a metodologia de Rezende (2008). A despeito de sua simplicidade, ela consegue tratar adequadamente várias questões que aparecem em leilões de valores comuns. Embora tenha algumas limitações, o método de Rezende (2008) permite obter estimativas estruturais (portanto, providas de causalidade) dos parâmetros do modelo. ${ }^{3}$

Sobre os resultados, há indicação de que os efeitos da "maldição do vencedor" de fato se manifestam nas estratégias adotadas pelas empresas nos leilões de petróleo e gás no Brasil. Também são encontradas evidências de que a presença da Petrobras tem efeito positivo no valor dos lances ofertados. Além disso, consórcios entre empresas aparentemente não têm motivação anticompetitiva. Por fim, não há indícios da existência de sinergias entre os blocos. Desse modo, embora haja espaço para melhora no desenho das licitações promovidas no Brasil, o desempenho dos leilões selados de primeiro preço (sem a possibilidade de lances por pacotes de blocos) não tende a ser muito inferior às alternativas possíveis.

$O$ restante do artigo se divide em seis seções. Na seção 2 é apresentada a legislação sobre os leilões de petróleo e gás no Brasil. Na seção 3 se discute a teoria dos leilões aplicada ao setor de petróleo e gás. Na seção 4 é apresentada a metodologia que será utilizada. Na seção 5 é brevemente apresentada a base de dados e algumas estatísticas descritivas importantes para a análise. Na seção 6 são apresentados

\footnotetext{
${ }^{1}$ Ver Rodriguez et alii (2008) para uma análise mais geral dos resultados dos leilões.

${ }^{2}$ Ver também Furtado et alii (2008).

${ }^{3}$ Ressalte-se que Motta e Ribeiro (2010) também usam o método de Rezende (2008).
} 
os resultados dos modelos econométricos estimados, com uma discussão detalhada dos impactos dos diferentes determinantes do lance vencedor. Por fim, a última seção apresenta brevemente algumas conclusões.

\section{LEGISLAÇÃO}

Até 1997, com exceção da distribuição e revenda de combustíveis, todas as atividades ligadas ao setor de hidrocarbonetos, como pesquisa, lavra das jazidas, desenvolvimento, produção, refino, transporte, importação e exportação eram monopólio da União. No entanto, um novo marco regulatório para o setor foi estipulado pela Lei do Petróleo (Lei $\mathrm{n}^{o}$ 9.478/1997), permitindo que empresas privadas desenvolvessem tais atividades.

A mesma lei criou a Agência Nacional do Petróleo (posteriormente, Agência Nacional do Petróleo, Gás Natural e Biocombustíveis, ANP) para regular o setor. Foi definida como uma de suas atribuições a elaboração dos editais e a promoção dos leilões para a concessão dos blocos para que as empresas explorem, desenvolvam e produzam petróleo comercializável, além da execução e fiscalização dos contratos resultantes desses leilões. Nesse caso, a presença do regulador se justifica pela existência de falhas de mercado, em particular do fato de o petróleo ser um recurso de propriedade comum. Este tipo de recurso apresenta duas características particulares, a saber, rivalidade e não exclusividade. A primeira característica é conferida a recursos cujo consumo por um indivíduo implica na redução da quantidade disponível para o consumo dos demais indivíduos, enquanto a não exclusividade significa que não é possível estabelecer os direitos de propriedade. Por esse motivo, caso não haja regulação, as empresas têm o incentivo de sobreperfurar poços para produzir a máxima quantidade possível. No entanto, tal comportamento culmina na queda rápida na pressão da reserva de petróleo, reduzindo a quantidade de petróleo passível de ser extraída. Ou seja, muitos poços perfurados na mesma área reduzem a capacidade total da reserva [Hernandez-Perez (2011a)].

Para uma empresa ser habilitada a participar dos leilões deve passar por alguns critérios técnicos, jurídicos e financeiros, estipulados nos editais publicados pela ANP. Nesse sentido, as empresas podem ser classificadas em três categorias. A categoria A permite que a empresa atue em blocos de petróleo localizados em terra, águas rasas ou profundas. ${ }^{4}$ Na categoria $\mathrm{B}$, a licitante pode oferecer lances e desenvolver atividades em blocos de terra ou águas rasas, sem a necessidade de formação de consórcios. Para atividades em águas profundas, é necessário que a mesma se una a um consórcio cuja operadora seja da categoria A. Por fim, a categoria C permite que a empresa opere apenas em blocos localizados em terra. No caso de blocos em água, deve se unir a um consórcio cuja operadora seja de no mínimo categoria $\mathrm{B}$, para águas rasas, ou A, para águas profundas.

Além desta qualificação, a empresa deve manifestar previamente o interesse nos blocos de determinado setor (ou conjunto de setores) e pagar uma taxa de participação. As empresas ou consórcios qualificados para participar dos leilões oferecem lances em envelopes fechados e de modo simultâneo. Lances para blocos de um mesmo setor podem ser oferecidos em um mesmo envelope. Desse modo, um participante não tem conhecimento exato de quais são os seus concorrentes em determinado bloco, mas apenas do setor em que determinado consórcio participa do leilão. Vencido o prazo para a entrega dos envelopes, eles são abertos ao público. Vence o leilão a empresa ou consórcio que obtiver o maior número de pontos, composto por quatro componentes.

O primeiro corresponde ao bônus de assinatura, que corresponde ao pagamento em valores monetários. O segundo e o terceiro se referem aos percentuais de compromisso com a aquisição local de bens e serviços nas fases de exploração e de desenvolvimento. Por sua vez, o quarto componente diz

\footnotetext{
${ }^{4}$ Um bloco é classificado como de águas profundas se estiver localizado sob uma lâmina de água média superior a 400 metros. Para valores inferiores a 400 metros, o bloco é definido como de águas rasas. São considerados blocos em terra também aqueles situados sob o leito de rios, como alguns blocos da bacia do Rio Amazonas.
} 
respeito ao programa exploratório mínimo. Para a obtenção da pontuação final, esses componentes são ponderados por pesos que diferem substancialmente ao longo das rodadas.

Nas quatro primeiras rodadas a proporção referente ao bônus de assinatura equivalia a $85 \%$ da pontuação final e o conteúdo local, $15 \%$, sendo $3 \%$ do ofertado na fase de exploração do bloco e $12 \%$ no desenvolvimento do campo. O programa exploratório mínimo não tinha nenhum peso, pois era determinado pelo regulador nos contratos e não fazia parte do lance ofertado. Nas duas rodadas subseqüentes o bônus de assinatura, conteúdo local na exploração e desenvolvimento e o programa exploratório tiveram pesos de $30 \%, 15 \%, 25 \%$ e $30 \%$, respectivamente. Nas demais rodadas os respectivos pesos passaram a ser de $40 \%, 5 \%, 15 \%$ e $40 \%$.

Note que é possível que um lance seja o vencedor sem que ofereça o maior bônus de assinatura. Nas quatro primeiras, como o peso desse componente era grande (85\%), raramente o vencedor do leilão não ofereceu o maior bônus (ocorreu apenas uma vez no total de 42 blocos que receberam mais de um lance nestas rodadas). Nas demais rodadas, em que o peso desse componente foi reduzido, são mais comuns vencedores que não oferecem o maior bônus de assinatura.

Após a definição do vencedor, a concessão para a exploração do bloco é consignada e pode durar até 35 anos, incluindo as fases de exploração e produção. Ao término deste tempo, as áreas devem retornar ao controle da União, detentora do monopólio sobre elas. A fase de exploração dura de três a oito anos, variando de acordo com o programa exploratório mínimo proposto pelo consórcio ganhador e com a norma pré-estabelecida nos editais. Na primeira etapa são realizados estudos geofísicos e geológicos detalhados e coleta de materiais sedimentares que ajudam a determinar a probabilidade de encontrar hidrocarbonetos no subsolo da área concedida. No segundo período, além de novos levantamentos técnicos, deve ser perfurado pelo menos um poço exploratório no bloco. Ao final de cada um dos períodos, o concessionário pode optar por devolver a área concedida à agência reguladora para que ela seja leiloada novamente. Ele também pode vendê-la a qualquer momento a outra empresa interessada em explorá-la.

A cada ano que decide permanecer com o bloco na fase de exploração, o concessionário está sujeito ao pagamento de uma taxa pela retenção da área, paga por metro quadrado mantido sob concessão e que varia de acordo com o bloco. Esta taxa serve para reduzir o incentivo que o concessionário teria em manter as áreas como reserva de valor e, por isso, esperar que o preço do petróleo atinja determinado nível que considere rentável o suficiente para começar a explorá-la. Outro objetivo da taxa é evitar que os concessionários esperem que empresas concessionárias de áreas vizinhas realizem levantamentos e anunciem suas descobertas para se aproveitar dos resultados encontrados.

Ao final do segundo período de exploração, se desejar manter a concessão, o concessionário deve declarar a comercialidade do bloco (ou da parte dele que deseja manter) e submeter ao regulador um plano de desenvolvimento para a área. Se aprovado, este plano determina o caminho a ser percorrido até o início da produção. Então, o bloco (ou a parte declarada comercial) ganha uma nova denominação e passa a ser tratado como um campo de produção. O tempo de concessão do campo, que compreende a fase de produção de petróleo e/ou gás natural, é de 27 anos. Ao petróleo e ao gás extraídos, estão sujeitos royalties de até $10 \%$ da produção e participações especiais de até $40 \%$ sobre a receita líquida da produção. As participações especiais são cobradas apenas em alguns campos em que a rentabilidade é considerada muito elevada e é variável de acordo com localização da lavra, com a profundidade e com o número de anos em que o campo está em produção. Nos campos em terra, o concessionário deve ainda pagar até o equivalente a $1 \%$ da produção total de petróleo e/ou gás natural do campo ao proprietário da terra, quando esta for de propriedade de um terceiro.

\section{TEORIA DOS LEILÕES E A INDÚSTRIA DE PETRÓLEO E GÁS}

Diferentes países adotam mecanismos distintos para definir direitos de exploração de reservas de petróleo e gás, mas boa parte deles o faz por meio de leilões. Nesse sentido, as características dos parti- 
cipantes e do objeto leiloado são fundamentais para definir adequadamente os detalhes do mecanismo de leilão. No caso de blocos de petróleo e gás, pelo menos três características chamam atenção.

Em primeiro lugar, trata-se de leilão de objeto de valor comum, ou seja, as reservas possuem o mesmo valor para todas as empresas, mas este é desconhecido no momento do leilão por conta da incerteza geológica. ${ }^{5}$ Sendo assim, os participantes estão sujeitos a um fenômeno conhecido como "maldição do vencedor". Intuitivamente, ganhar o leilão é uma má notícia para o ganhador a respeito do verdadeiro valor do objeto, pois indica que nenhum outro participante estaria disposto a ofertar um lance tão alto. Nesse caso, é bastante provável que a estimativa do valor do objeto feita pelo vencedor do leilão esteja superestimada [Cramton (2007)]. ${ }^{6}$

Desse modo, participantes que não condicionarem seus lances à possibilidade de ocorrência da "maldição do vencedor" tendem a pagar muito mais pelo objeto do que ele realmente vale. Do ponto de vista da teoria econômica, no leilão selado de primeiro preço dois fatores atuariam em direções opostas. Por um lado, o aumento no número de participantes implica que o jogador deve ofertar um lance maior para ganhar. Por outro lado, quanto mais concorrentes, maior a chance de ocorrer a "maldição do vencedor", fazendo com que os participantes reduzam seus lances para evitar que isso ocorra [Thaler (1988)]. A evidência sugere que de fato os participantes de leilões de petróleo (nos Estados Unidos) levam em consideração o fenômeno da "maldição do vencedor" em seus lances e se comportam de acordo com a previsão da teoria [Hendricks et alii (2003)].

Além disso, do ponto de vista da teoria econômica, mais variância nas estimativas do valor do bloco tende a reduzir o valor do lances [Milgrom e Weber (1982), Brannman et alii (1987)]. Por esse motivo, diversos tipos de informações geológicas sobre os blocos são tornados públicos pela ANP, auxiliando na formação das expectativas sobre o seu valor e reduzindo os efeitos negativos da "maldição do vencedor" nas receitas obtidas nos leilões.

Em segundo lugar, a incerteza geológica pode gerar assimetria de informação. Mesmo que tenham acesso às mesmas informações geológicas sobre o bloco, as empresas podem ter interpretações muito diferentes quanto ao valor do mesmo. Em particular, empresas com um histórico de produção em blocos próximos tendem a prever com maior exatidão o potencial de uma determinada reserva. ${ }^{7}$ Esse é tipicamente o caso da Petrobras no Brasil, pois durante muitos anos ela foi a única a ter o direito de explorar petróleo em território brasileiro. ${ }^{8}$ Nesse sentido, a presença de agentes informados acentua o fenômeno da "maldição do vencedor". A teoria econômica indica que, condicionado a toda informação pública disponível, os participantes informados tendem ofertar lances com maior freqüência, mas de magnitude inferior ao dos participantes não informados em leilões selados de primeiro preço [Hendricks et alii (1994)]. ${ }^{9}$

Ademais, a incerteza geológica tende a induzir a formação de consórcios para a exploração e produção de petróleo e gás. ${ }^{10}$ Trata-se de estratégia bastante comum no setor para mitigar os riscos associados à atividade [Hendricks e Porter (1992)]. No Brasil não é diferente. Em particular, muitas empresas procuram formar consórcios com a Petrobras para exploração de petróleo e gás em território brasileiro.

\footnotetext{
${ }^{5}$ Ver Hendricks et alii (1987) para evidências a esse respeito. Em Li e I. (2000) define-se um modelo híbrido, que tem como casos particulares e polares os leilões de valores comuns e os de valores privados independentes. A partir desse modelo, os autores estimam a distribuição dos componentes privados e comuns dos valores atribuídos aos blocos de petróleo nos Estados Unidos. Em Campo et alii (2003) o mesmo é feito levando-se em consideração a possibilidade de assimetria entre os participantes dos leilões.

${ }^{6}$ Os pioneiros na discussão desse fenômeno no contexto de leilões de blocos de petróleo e gás foram Capen et alii (1971).

${ }^{7}$ Ver Hendricks et alii (1987) para evidências a esse respeito.

${ }^{8}$ Para evidências e este respeito ver Brasil et alii (2008) e Matoso (2009).

${ }^{9}$ Para uma análise do papel da informação nos leilões de blocos de petróleo e gás nos Estados Unidos ver Hendricks et alii (1993) e Porter (1995).

${ }^{10}$ Além da incerteza geológica, outros fatores como riscos de mercado e o grande requerimento de capital para explorar e produzir petróleo e gás também explicam a formação de consórcios.
} 
No entanto, as autoridades de defesa da concorrência de alguns países já manifestaram preocupação com a potencial redução na competição advinda desses consórcios. Nos Estados Unidos, por exemplo, as maiores empresas do setor chegaram a ser proibidas de fazerem consórcios entre si para evitar a colusão entre elas. Entretanto, as evidências sugerem que a formação de consórcios é consistente com comportamento mais competitivo e não com práticas anticompetitivas [Mead et alii (1986), Hoffman et alii (1991)]. ${ }^{11}$

Por último, os valores de diferentes blocos podem não ser independentes. A soma dos valores de blocos próximos sob a mesma propriedade pode ser diferente da soma desses mesmos valores sob propriedade de empresas distintas. Em caso de igualdade, diz-se que os valores são aditivos. Se o valor do pacote de blocos é menor do que a soma dos valores individuais, diz-se que os valores são subaditivos. Blocos adicionais têm menos valor para as empresas, por exemplo, se elas não têm recursos suficientes para explorá-lo de forma eficiente [Cramton (2007)]. Se o valor do pacote é maior do que as somas dos valores individuais, diz-se que os valores são superaditivos. Nesse caso, há sinergias em explorar blocos na mesma região. Essas sinergias podem ser resultado de compartilhamento de infraestrutura, da possibilidade de se evitar os custos associados à unitização de blocos contíguos ou de externalidades informacionais por conta da proximidade entre os blocos.

Um aspecto da teoria relacionado às externalidades informacionais de blocos próximos é que o regulador deve estipular prazos e regras na fase de exploração do bloco para que o consórcio vencedor efetivamente busque por petróleo. Caso contrário, o bloco servirá apenas como uma opção de hedge contra incertezas econômicas e flutuações do preço do petróleo. Os atrasos nas perfurações ocorrem, por exemplo, quando dois ou mais grupos de empresas dividem o mesmo depósito petrolífero. Segundo Hendricks e Kovenock (1989), cada firma deixa a outra incorrer no custo de perfuração do poço. Assim, o regulador deve especificar o prazo máximo de exploração, com multas em caso de descumprimento. A ANP estipula tais limites, conforme já explicitado em seção anterior. No entanto, o arremate de blocos vizinhos em rodadas distintas gera um componente estratégico adicional a ser considerado na formação do lance de cada participante. Blocos adjacentes já vendidos em rodadas anteriores podem valorizar os blocos objeto de leilão, mesmo que ainda não tenha sido declarada a sua comercialidade.

\section{METODOLOGIA}

\subsection{Leilões de Valores Privados Independentes}

Para a análise dos determinantes dos lances nos leilões de blocos de petróleo no Brasil será seguida a metodologia de Rezende (2008). Trata-se de metodologia que, a despeito de sua simplicidade, permite estimar os parâmetros estruturais da distribuição dos valores atribuídos aos blocos pelas empresas. Nesse sentido, muitos estudos estimam regressões do seguinte tipo:

$$
p=X \beta+u,
$$

em que $p$ é o preço de transação do bem leiloado, $X$ é um vetor de regressores e $u$ é um termo aleatório.

Principalmente em leilões de primeiro preço, o jogador nunca submete um lance que seja sua real apreciação do bem. Desse modo, a forma reduzida apresentada em (1) não consegue identificar adequadamente os parâmetros da distribuição das avaliações que os jogadores fazem do objeto leiloado. Para contornar esta dificuldade, Rezende (2008) modela os parâmetros de localização (média) e escala (variância) dessa distribuição.

Nesse sentido, seja $V_{i l}$ o valor atribuído pelo jogador $i$ no $l$-ésimo leilão, em um total de $L$ leilões. Seja $\mu_{l}$ a média e $\sigma_{l}$ o desvio-padrão de tais apreciações. Ademais, definam-se as quatro hipóteses a seguir.

\footnotetext{
${ }^{11}$ Para uma análise dos fatores que influenciam a formação de consórcios em leilões de blocos de petróleo ver Hendricks et alii (2008).
} 
Hipótese 1 (Independência). $V_{i l}=\mu_{l}+\sigma_{l} \varepsilon_{i l}$, em que $\varepsilon_{i l}$ são independentemente e identicamente disbribuído com distribuição $F$.

Hipótese 2 (Linearidade). $\mu_{l}=X_{l} \beta$ e $\sigma_{l}=Z_{l} \alpha$.

Hipótese 3. As regras do leilão são tais que o bem é sempre atribuído ao jogador que tem a maior valoração do bem, e o jogador com menor valor espera pagar um valor nulo.

Hipótese 4 (Exogeneidade). O número de jogadores, $n_{l}$, é exógeno e de conhecimento comum. Licitantes são neutros ao risco, e maximizam seus lucros a cada leilão separadamente

A Hipótese 1 é feita para simplificar os cálculos para que o valor padronizado $\varepsilon_{i l}=\left(V_{i l}-\mu_{l}\right) / \sigma_{l}$ tenha uma distribuição comum $F$ que não varie entre os leilões e jogadores, além de ser independente. Essa hipótese é um requisito padrão em um contexto de valorizações simétricas e independentes. A Hipótese 2 também é feita por simplicidade: os resultados são válidos também para mínimos quadrados não-lineares. A Hipótese 3 é válida no contexto de leilões de primeiro preço, tal como ocorre no caso analisado. Por sua vez, a Hipótese 4 pode limitar o uso do método no contexto dos leilões de blocos de petróleo e gás no Brasil, na medida em que o número de participantes tende a ser endógeno, visto que os blocos mais rentáveis tendem a atrair mais participantes e que a ANP impõe um lance mínimo, o que para alguns participantes pode ser uma restrição de exclusão. ${ }^{12}$

A partir do Teorema da Equivalência da Receita Esperada (Myerson, 1981) é possível obter:

$$
\begin{aligned}
E\left[p_{l} \mid X_{l}, Z_{l}, n_{l}\right] & =E\left[V_{\left(2: n_{l}\right)} \mid X_{l}, Z_{l}, n_{l}\right], \\
& =E\left[\mu_{l}+\sigma_{l} \varepsilon_{\left(2: n_{l}\right)} \mid X_{l}, Z_{l}, n_{l}\right], \\
& =\mu_{l}+\sigma_{l} E\left[\varepsilon_{\left(2: n_{l}\right)}\right], \\
& =X_{l} \beta+Z_{l} \alpha a\left(n_{l}\right),
\end{aligned}
$$

em que, $V_{\left(2: n_{l}\right)}$ é a estatística de segunda ordem entre as apreciações de todos os jogadores.

Ou seja, a aplicação do teorema na primeira igualdade mostra que o valor esperado do lance vencedor para o bem será igual à segunda maior valoração entre os participantes do leilão. Assim, é possível estabelecer uma relação entre os determinantes do lance vencedor do leilão e o que determina a valoração atribuída ao bloco leiloado. Utilizando algumas propriedades de estatísticas de ordem e as hipóteses anteriores chega-se a última igualdade, em que $a\left(n_{l}\right)=E\left[\varepsilon_{\left(2: n_{l}\right)}\right]$. Desse modo, basta a aplicação do método de Mínimos Quadrados Ordinários (MQO) para a obtenção de estimativas de $\beta$ e $\alpha$ não-viesadas e consistentes, pois o modelo é linear nos parâmetros e os regressores não são endógenos (por hipótese). No caso de uma distribuição $F$ desconhecida, Rezende (2008) propõe flexibilizar a estimativa do termo $a\left(n_{l}\right)$ : incluir variáveis dummies $d_{k l}$ para o caso em que $n_{l}=k$, ou seja, variáveis binárias que indiquem quando o número de participantes for igual a um, dois, três e assim por diante.

Considere-se o caso homocedástico, quando $\sigma_{l}=\sigma$, ou seja, quando $Z_{l}$ contém apenas a constante. Reescrevendo a forma funcional da média como $\mu_{l}=X_{l} \beta=\beta_{0}+x_{l} \beta_{1}$, e substituindo em (2) tem-se:

$$
E\left[p_{l} \mid X_{l}, Z_{l}, n_{l}\right]=x_{l} \beta_{1}+\sum_{k} d_{k l}\left[\beta_{0}+\sigma a(k)\right]=x_{l} \beta_{1}+\sum_{k} d_{k l} \delta_{k},
$$

em que o somatório no $k$ é sobre os possíveis valores de $n_{l}$ e $\delta_{k}=\beta_{0}+\sigma a(k)$. Para obter estimativas dos parâmetros que afetam apenas a média, basta aplicar o método de MQO, regredindo $p_{l}$ contra $x_{l}$

\footnotetext{
${ }^{12} \mathrm{O}$ objetivo deste artigo é lançar um primeiro olhar sobre os determinantes dos lances em leilões de petróleo e gás no Brasil. Nesse sentido, optou-se por um método que permite, de modo simples, identificar parâmetros estruturais do modelo. Sendo assim, a correção do problema de endogeneidade não será objeto deste artigo, pois implicaria adotar métodos econométricos muito mais sofisticados e complexos [ver Athey e Haile (2002) e Bajari e Hortacsu (2003), por exemplo].
} 
e as dummies $d_{k l}$. O intercepto $\beta_{0}$ não pode ser identificado e será absorvido pelos coeficientes das dummies $d_{k l}$.

Nesse sentido, optou-se por incluir em $x_{l}$ as seguintes variáveis explicativas: (i) dummies para localização do bloco, ou seja se está em terra (omitida), águas rasas (RASA) ou águas profundas (PROFUNDA); (ii) logaritmo do número de poços perfurados antes da rodada dentro de cada bloco, por $\mathrm{km}^{2}$ (POÇOS); (iii) logaritmo do número de vezes que um mesmo bloco foi colocado em leilão (REPET); (iv) logaritmo da área de cada bloco em $\mathrm{km}^{2}$ (AREA); (v) logaritmo do número de blocos oferecidos por bacia em cada rodada (BLOCOS); (vi) dummies para o tipo de consórcio - empresa pequena sozinha ( $P$ ), empresa grande sozinha $(G)$, pelo menos uma empresa pequena e uma grande $(P G)$, pelo menos duas empresas grandes (GG) e somente empresas pequenas (omitida); (vii) logaritmo do preço do petróleo bruto (BRENT); (viii) variável binária indicando a presença de blocos vizinhos leiloados em rodadas anteriores (VIZINHO).

\subsection{Leilões de Valores Comuns}

No entanto, o modelo descrito em (3) não é adequado em um ambiente de leilões de valores comuns, pois depende da aplicação do Teorema da Equivalência da Receita Esperada, que é válido apenas para valores privados independentes. Os leilões de blocos de petróleo e gás tendem a ser de valores comuns com sinais privados dependentes. Segundo Menezes (1994), a estimativa do valor do bem para cada participante depende de informação que é comum a todos os participantes. Assim, se um consórcio acredita que a reserva de petróleo é muito valiosa, então também espera que os outros participantes também considerem a área de alto valor. Nesse caso, os sinais serão correlacionados e, portanto, os valores não são independentes. Felizmente, é possível adaptar o método proposto em Rezende (2008) para contextos mais gerais.

Seja $R_{l}$ um vetor de variáveis que captura todas as mudanças ocorridas entre os leilões. Seja também uma versão mais geral da Hipótese 1 .

Hipótese 5 (Independência condicional a $\left.R_{l}\right)$. $V_{i l}=\mu_{l}+\sigma_{l} \varepsilon_{i l}$, em que $\varepsilon_{i l}$, as valorações padronizadas, condicional em $R_{l}$, têm a mesma distribuição entre os leilões (e são independentes entre os leilões).

No caso de leilões de valores comuns, como as valorações não são independentes, o preço esperado no leilão passa a depender não somente de $n_{l}$ mas também de $R_{l}$. Em outras palavras o modelo (3) pode ser adaptado para além do contexto de valores privados independentes, bastando considerar um conjunto maior de variáveis:

$$
E\left[p_{l} \mid X_{l}, Z_{l}, n_{l}\right]=X_{l} \beta+Z_{l} \alpha \tilde{a}\left(R_{l}\right)
$$

em que, $\tilde{a}\left(R_{l}\right)$ exerce o mesmo papel que $a\left(n_{l}\right)$, mas com um número maior de variáveis. Nesse sentido, foram incluídos em $R_{l}$ : (i) variáveis dummies para cada rodada, refletindo mudanças de regras que ocorreram ao longo do tempo; ${ }^{13}$ (ii) dummies para número de participantes, já consideradas no modelo (3); (iii) variável indicadora de empresa informada (PETROBRAS), indicando se a Petrobras participou do leilão.

Novamente, para obter estimativas dos parâmetros que afetam apenas a média, basta aplicar o método de MQO, regredindo $p_{l}$ contra $x_{l}$, as variáveis contidas em $R_{l}$ e todas a suas possíveis interações. Em outras palavras, além das variáveis dummies $d_{k l}$, das variáveis dummies para rodadas e da variável binária indicadora de participante informado (PETROBRAS), serão incluídas todas as possíveis interações entre elas.

Vale notar que todas as variáveis incluídas em $R_{l}$ não entram na especificação da média, mas apenas na flexibilização da estimativa de $\tilde{a}\left(R_{l}\right)$. Logo, são dificeis de interpretar. Por exemplo, a variável

\footnotetext{
${ }^{13}$ Logicamente, essas variáveis capturam não apenas mudanças de regras entre as rodadas, mas qualquer choque econômico que tenha afetado igualmente todos os participantes daquela determinada rodada.
} 
PETROBRAS é um sinal comum a todos os participantes (inclusive Petrobras). Ou seja, a inclusão da variável PETROBRAS não permite avaliar diferenças de comportamento dos participantes em relação à presença do agente informado. Não é possível usar esta informação para inferir sobre a natureza da assimetria entre os jogadores. Novamente, trata-se apenas de um sinal comum a todos os agentes a respeito da presença do agente informado e a inclusão da variável PETROBRAS somente permite controlar os resultados para a assimetria informacional.

Além disso, é importante esclarecer um aspecto sobre a interpretação dos parâmetros associados aos regressores que entram na especificação da média $\left(x_{l}\right)$. O método de Rezende (2008) somente permite identificar o impacto desses regressores na média se este se manifesta da mesma maneira para todos os participantes do leilão. Não é possível, por exemplo, identificar se o preço do petróleo afeta a avaliação dos blocos de modo distinto para empresas pequenas e empresas grandes.

\section{BASE DE DADOS E ESTATÍSTICAS DESCRITIVAS}

A base de dados utilizada neste estudo foi construída a partir do cruzamento de informações públicas contidas nos websites da ANP. ${ }^{14}$ Ela contém informações sobre os blocos e suas características mais gerais (localização e área, por exemplo), dos leilões (lances e empresas participantes, por exemplo) e dos poços perfurados (informações extraídas do BDEP - Banco dos Dados de Exploração e Produção).

A variável dependente ( $L A N C E$ ) foi definida como o logaritmo natural do maior bônus de assinatura oferecido por cada bloco (em moeda doméstica, a preços de 2010). Como a ponderação de cada componente (bônus, conteúdo local e programa exploratório mínimo) na pontuação final de cada consórcio mudou muito ao longo dos anos, o bônus de assinatura foi utilizado por ser o único expresso em termos monetários, permitindo a comparação entre diferentes rodadas. Nesse sentido, embora não seja o único componente dos lances, trata-se de uma boa aproximação para a pontuação de cada consórcio, pois para a maior parte dos blocos comprados (aproximadamente 95\%) o lance vencedor em termos de pontos também foi o que apresentou maior bônus de assinatura.

A Tabela 1 apresenta a descrição e algumas estatísticas descritivas das variáveis utilizadas. Note-se que a maior parte de blocos vendidos está em terra, pois possuem bônus de assinatura mínimo menor do que os blocos marítimos e exigências inferiores em termos de capital e experiência operacional. Ademais, ressalte-se que a Petrobras participou de $58 \%$ dos leilões em que o bloco foi efetivamente comprado.

Com relação aos blocos comprados pelo valor mínimo ou algum valor próximo, estes são uma parcela pequena da amostra. Os lances até R\$ 1000 superiores ao bônus mínimo correspondem a apenas 7,79\% de todos os lances (ou 8,87\% dos lances ganhadores).

Cabe ressaltar que somente foram incluídos na amostra os blocos vendidos, ou seja, estão sendo usadas apenas as informações que revelam o valor que as empresas atribuem aos blocos. De fato, dos 3.794 blocos ofertados pela ANP, apenas 790 foram comprados (21\%). A ocorrência de blocos não vendidos se tornou especialmente relevante a partir da Quinta Rodada, quando a ANP aumentou o número de blocos ofertados e diminuiu seu tamanho médio. A título de comparação, na Segunda Rodada foram ofertados 23 blocos com uma área média de $2.580 \mathrm{~km}^{2}$ e 21 foram vendidos $(91,3 \%$, a maior porcentagem de vendas dentre todas as rodadas). Por sua vez, na Quinta Rodada foram oferecidos 908 blocos com área média de $179 \mathrm{~km}^{2}$ e apenas 101 foram vendidos $(11,1 \%$, a menor porcentagem dentre todas as rodadas). Por fim, a ANP diminuiu o número de blocos ofertados a partir da Oitava Rodada, mas não a ponto de alcançar valores baixos como nos primeiros leilões, e aumentou ligeiramente o tamanho médio (de $351 \mathrm{~km}^{2}$ na Sétima Rodada para $358 \mathrm{~km}^{2}$ na Oitava Rodada).

\footnotetext{
${ }^{14}$ Trata-de de base de dados muito semelhante a usada por Hernandez-Perez (2011b).
} 


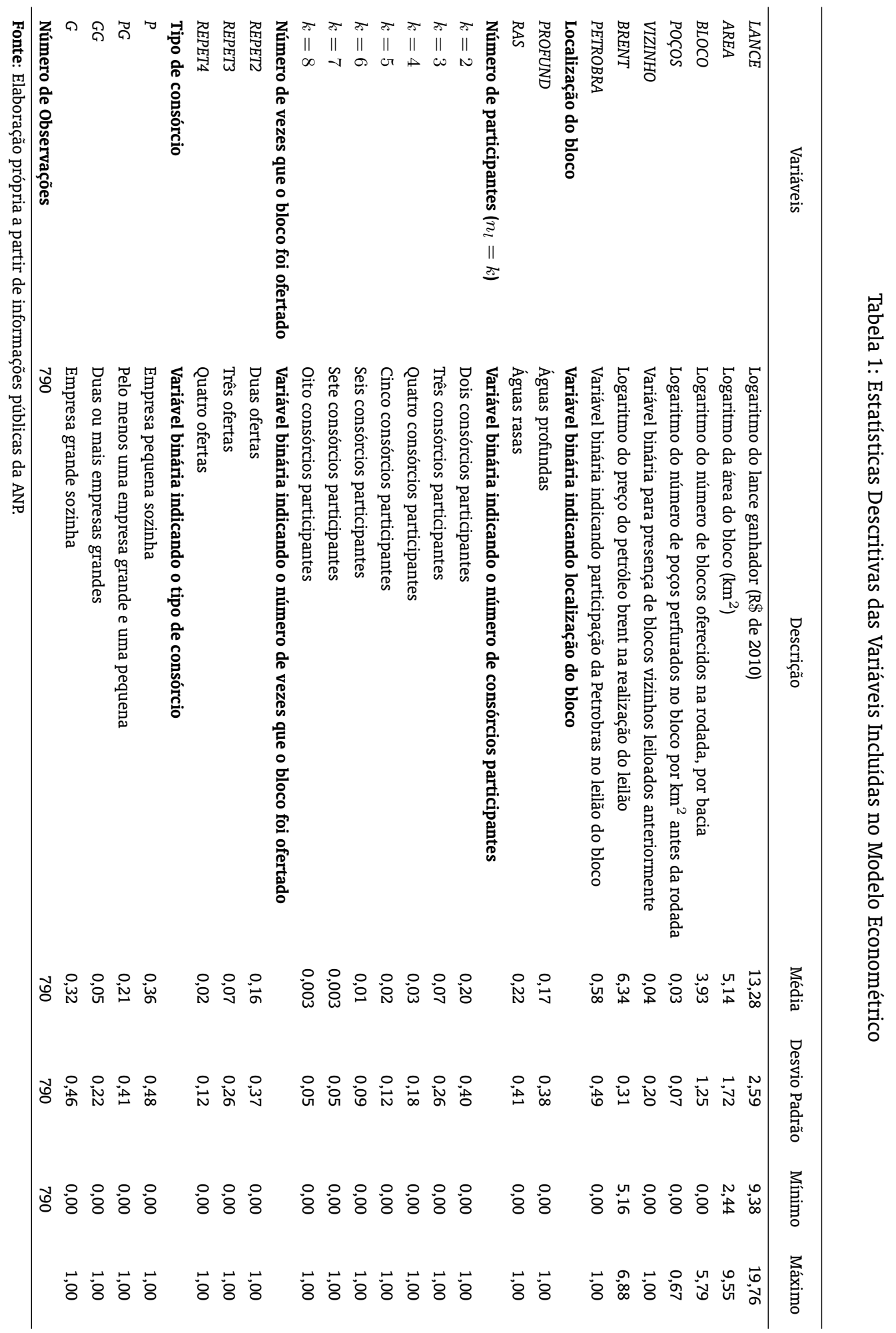




\section{RESULTADOS}

A Tabela 2 apresenta os resultados da estimação de diferentes especificações do modelo mais geral proposto por Rezende (2008), aplicável a um contexto de leilões de valores comuns. Na especificaçao (C) o vetor de variáveis $R_{l}$ inclui dummies para $n_{l}$ e para rodadas, estas últimas capturando qualquer tipo de mudança ocorrida ao longo do tempo (regras dos leilões e cenários econômicos, por exemplo), além de todas as possíveis interações entre essas variáveis binárias. Na especificação (D) inclui-se adicionalmente ao vetor $R_{l}$ uma variável indicadora da presença do competidor informado (PETROBRAS), além de todas as possíveis interações entre essa variável e as demais. Na especificação (E) adiciona-se uma variável indicadora da existência de bloco vizinho vendido em rodadas anteriores (VIZINHO), bem como todas as interações entre essa variável e as demais.

A título de comparação também foram apresentados os resultados de uma especificação na forma reduzida - especificação (A) - e de uma especificação do modelo de Rezende (2008) para leilões valores privados independentes - especificação (B) - na qual somente as dummies para $n_{l}$ foram incluídas em $R_{l}{ }^{15}$

Tabela 2: Resultados da Estimação de Diferentes Especificações do Modelo (4)

\begin{tabular}{|c|c|c|c|c|c|}
\hline & (A) & (B) & (C) & (D) & (E) \\
\hline \multirow{2}{*}{ AREA } & $0,361^{* *}$ & $0,316^{* *}$ & $0,391^{* *}$ & $0,391^{* *}$ & $0,401^{* *}$ \\
\hline & {$[0,167]$} & {$[0,160]$} & {$[0,164]$} & {$[0,167]$} & {$[0,167]$} \\
\hline \multirow{2}{*}{ BLOCOS } & $-1,081^{* * *}$ & $-0,940^{* * *}$ & $-0,132$ & $-0,118$ & $-0,118$ \\
\hline & {$[0,109]$} & {$[0,113]$} & {$[0,210]$} & {$[0,224]$} & {$[0,221]$} \\
\hline \multirow{2}{*}{ POÇOS } & $3,501^{* * *}$ & $2,383^{* *}$ & $2,354^{* *}$ & $1,952^{*}$ & $1,886^{*}$ \\
\hline & {$[0,949]$} & {$[1,047]$} & {$[1,016]$} & {$[0,997]$} & {$[0,998]$} \\
\hline \multirow{2}{*}{ VIZINHO } & - & - & - & - & 0,386 \\
\hline & & & & & {$[0,346]$} \\
\hline \multirow{2}{*}{ BRENT } & $1,213^{* * *}$ & $1,391^{* * *}$ & $0,876^{* *}$ & $0,853^{* *}$ & $0,854^{* *}$ \\
\hline & {$[0,377]$} & {$[0,370]$} & {$[0,408]$} & {$[0,424]$} & {$[0,421]$} \\
\hline \multirow{2}{*}{ PROFUNDA } & $2,710^{* * *}$ & $3,055^{* * *}$ & $2,616^{* * *}$ & $2,571^{* * *}$ & $2,520^{* * *}$ \\
\hline & {$[0,590]$} & {$[0,487]$} & {$[0,561]$} & {$[0,612]$} & {$[0,610]$} \\
\hline \multirow{2}{*}{ RASA } & $1,134^{*}$ & $1,609^{* * *}$ & $1,698^{* * *}$ & $1,660^{* * *}$ & $1,630^{* * *}$ \\
\hline & {$[0,640]$} & {$[0,545]$} & {$[0,562]$} & {$[0,590]$} & {$[0,589]$} \\
\hline \multirow{2}{*}{$P$} & $-0,286$ & $-0,25$ & $-0,310^{*}$ & $-0,225$ & $-0,225$ \\
\hline & {$[0,212]$} & {$[0,207]$} & {$[0,182]$} & {$[0,207]$} & {$[0,208]$} \\
\hline \multirow{2}{*}{$P G$} & 0,248 & 0,25 & 0,218 & $-0,227$ & $-0,217$ \\
\hline & {$[0,266]$} & {$[0,257]$} & {$[0,229]$} & {$[0,274]$} & {$[0,275]$} \\
\hline \multirow{2}{*}{ GG } & $1,839^{* * *}$ & $1,153^{* * *}$ & $1,344^{* * *}$ & $0,931^{* *}$ & $0,937^{* *}$ \\
\hline & {$[0,376]$} & {$[0,358]$} & {$[0,369]$} & {$[0,444]$} & {$[0,444]$} \\
\hline \multirow{2}{*}{ G } & $0,765^{* * *}$ & $0,572^{* *}$ & $0,900^{* * *}$ & $0,458^{*}$ & $0,464^{*}$ \\
\hline & {$[0,246]$} & {$[0,242]$} & {$[0,221]$} & {$[0,260]$} & {$[0,260]$} \\
\hline \multirow{2}{*}{ REPET2 } & $0,821^{* * *}$ & $0,753^{* * *}$ & 0,033 & $-0,011$ & $-0,001$ \\
\hline & {$[0,213]$} & {$[0,209]$} & {$[0,217]$} & {$[0,233]$} & {$[0,232]$} \\
\hline \multirow{2}{*}{ REPET3 } & $-0,332$ & $-0,457$ & $-0,995^{* * *}$ & $-0,949^{* *}$ & $-0,931^{* *}$ \\
\hline & {$[0,309]$} & {$[0,300]$} & {$[0,373]$} & {$[0,392]$} & {$[0,392]$} \\
\hline \multirow{3}{*}{ REPET4 } & 0,101 & $-0,708$ & $-1,045^{* *}$ & $-0,853^{*}$ & $-0,854^{*}$ \\
\hline & {$[0,554]$} & {$[0,644]$} & {$[0,501]$} & {$[0,503]$} & {$[0,504]$} \\
\hline & & & \multicolumn{3}{|c|}{ Continua na próxima página } \\
\hline
\end{tabular}

\footnotetext{
${ }^{15}$ Foram estimadas diversas especificações da forma reduzida, mas optou-se por apresentar apenas uma delas. Em caso de interesse, os resultados das demais especificações estão disponíveis junto aos autores.
} 


\begin{tabular}{|c|c|c|c|c|c|}
\hline & (A) & (B) & (C) & (D) & $(\mathrm{E})$ \\
\hline \multirow{2}{*}{$k=2$} & \multirow{2}{*}{-} & $1,138^{* * *}$ & 0,514 & 0,751 & 0,748 \\
\hline & & {$[0,143]$} & {$[0,583]$} & {$[0,559]$} & {$[0,556]$} \\
\hline \multirow{2}{*}{$k=3$} & \multirow{2}{*}{-} & $1,537^{* * *}$ & $3,032^{* * *}$ & $3,135^{* * *}$ & $3,134^{* * *}$ \\
\hline & & {$[0,220]$} & {$[0,605]$} & {$[0,609]$} & {$[0,606]$} \\
\hline \multirow{2}{*}{$k=4$} & \multirow{2}{*}{-} & $2,201^{\text {*** }}$ & $2,387^{* * *}$ & $3,478^{* * *}$ & $3,461^{* * *}$ \\
\hline & & {$[0,242]$} & {$[0,487]$} & {$[0,756]$} & {$[0,755]$} \\
\hline \multirow{2}{*}{$k=5$} & \multirow{2}{*}{-} & $2,344^{* * *}$ & $2,937^{* * *}$ & $4,125^{* * *}$ & $2,194^{* * *}$ \\
\hline & & {$[0,281]$} & {$[0,531]$} & {$[0,609]$} & {$[0,809]$} \\
\hline \multirow{2}{*}{$k=6$} & \multirow{2}{*}{-} & $2,746^{* * *}$ & $2,521^{* * *}$ & $2,190^{* * *}$ & $2,186^{* * *}$ \\
\hline & & {$[0,386]$} & {$[0,803]$} & {$[0,824]$} & {$[0,824]$} \\
\hline \multirow{2}{*}{$k=7$} & \multirow{2}{*}{-} & $3,378^{* * *}$ & $2,860^{* * *}$ & & $2,127^{* * *}$ \\
\hline & & {$[0,243]$} & {$[0,310]$} & & {$[0,400]$} \\
\hline \multirow{2}{*}{$k=8$} & \multirow{2}{*}{-} & $0,835^{*}$ & 0,755 & 0,145 & 0,143 \\
\hline & & {$[0,452]$} & {$[0,495]$} & {$[0,527]$} & {$[0,527]$} \\
\hline \multirow{2}{*}{ PETROBRAS } & \multirow{2}{*}{ NÃO } & \multirow{2}{*}{ NÃO } & \multirow{2}{*}{ NÃO } & $0,716^{* * *}$ & $0,717^{* * *}$ \\
\hline & & & & {$[0,259]$} & {$[0,259]$} \\
\hline Dummies para rodadas & NÃO & NÃO & SIM & SIM & SIM \\
\hline Interação entre número de participantes e rodadas & NÃO & NÃO & SIM & SIM & SIM \\
\hline Interação entre número de participantes e PETROBRAS & NÃO & NÃO & NÃO & SIM & SIM \\
\hline Interação entre número de participantes, PETROBRAS e rodadas & NÃO & NÃO & NÃO & SIM & SIM \\
\hline Dummies para setores & SIM & SIM & SIM & SIM & SIM \\
\hline Número de Observações & 790 & 790 & 790 & 790 & 790 \\
\hline $\mathrm{R}^{2}$ & 0,7 & 0,76 & 0,8 & 0,81 & 0,81 \\
\hline $\mathrm{R}^{2}$ Ajustado & 0,68 & 0,73 & 0,77 & 0,77 & 0,77 \\
\hline
\end{tabular}

Notas: Em todas as especificações a variável independente é LANCE. Os desvios-padrão robustos das estimativas são apresentados entre colchetes. O símbolo * indica significância a 10\%, ** indica significância a 5\% e ** significância a 1\%.

Da Tabela 2 nota-se que a maior parte dos coeficientes se mostrou robusta às diferentes especificações, principalmente quando se considera apenas aquelas que são adequadas aos leilões de valores comuns [especificações (C), (D) e (E)]. Entretanto, percebe-se também alguma robustez - mais quanto ao sinal dos coeficientes do que com relação a sua magnitude - quando se leva em consideração às especificações (A) e (B).

Efeitos da "Maldição do Vencedor" Com relação às variáveis indicadoras do número de participantes $\left(n_{l}\right)$, percebe-se que na especificação (B) o lance vencedor aumenta monotonamente até sete participantes (para um máximo de oito). A inclusão das dummies de rodada na especificação (C) desfaz a monotonicidade encontrada na especificação (B), mas é somente nas especificações (D) e (E), que incluem a variável indicadora do participante informado (PETROBRAS), que o padrão se torna mais claro. O lance tende a crescer até determinado ponto (quatro ou cinco participantes, dependendo da especificação) e depois passa a decrescer. Note-se que é justamente o comportamento previsto pela teoria econômica (ver seção 3), refletindo a tensão existente entre o aumento da competição e a severidade do efeito da "maldição do vencedor" na decisão das empresas sobre o valor dos lances ofertados.

Ainda sobre o efeito da "maldição do vencedor" na estratégia dos participantes do leilão, nota-se que o número de poços por $\mathrm{km}^{2}$ perfurados anteriormente (POÇOS), uma aproximação da informação pública disponível sobre o bloco, tem efeito positivo sobre o lance vencedor. ${ }^{16}$ Novamente, trata-se

\footnotetext{
${ }^{16}$ No entanto, a variável que indica a presença de blocos vizinhos leiloados em rodadas anteriores (VIZINHO), também relacionada à informação disponível, não se mostrou significativa [ver especificação (E)].
} 
de resultado previsto pela literatura. Ademais, é uma indicação de que a estratégia da ANP de revelar informações geológicas dos blocos antes dos leilões tem o efeito esperado em termos de aumento da arrecadação de bônus de assinatura.

Incerteza Geológica e Assimetria de Informação Das especificações (D) e (E) nota-se que os lances vencedores tendem a ser $105 \%$ maiores quando a Petrobras participa do leilão. ${ }^{17}$ Como esta empresa ganhou a maioria dos leilões dos quais participou, este efeito positivo é em grande parte devido aos lances maiores da própria Petrobras. ${ }^{18}$ No entanto, como já destacado na seção 4 , o coeficiente da variável PETROBRAS (e de todas as outras variáveis incluídas em $R_{l}$ ) é de difícil interpretação. Ele deve ser entendido apenas como um sinal da presença do agente informado, que é comum a todos os agentes, inclusive à própria Petrobras. O método de Rezende (2008) não permite avaliar a heterogeneidade do comportamento dos jogadores em relação a tal assimetria.

Nesse sentido, o resultado encontrado parece contradizer a previsão da teoria econômica: condicional a toda informação pública disponível, agentes informados tendem a ofertar lances inferiores (ver seção 3). Entretanto, mais do que evidência de fracasso da teoria, este resultado pode significar que existe um conjunto muito mais amplo de informação pública sobre os blocos que não é observável pelos econometristas. Nesse sentido, contornar essa limitação passa pelo uso de modelos mais sofisticados, que necessariamente fazem hipóteses mais fortes sobre a distribuição dos valores dos blocos [Hendricks et alii (1994)].

Ademais, a incerteza geológica tende a induzir a formação de consórcios entre as empresas para mitigar o risco associado a esse fator (ver seção 3). Entretanto, esses consórcios também podem ter motivações anticompetitivas, o que tem despertado a preocupação de autoridades de defesa da concorrência de alguns países. Nesse sentido, as evidências apresentadas na Tabela 2 indicam que, no caso brasileiro, consórcios entre empresas grandes $(G G)$ tendem a oferecer lances maiores do que empresas grandes sozinhas $(G)$. Desse modo, assim como no norte-americano [Mead et alii (1986), Hoffman et alii (1991)], a formação de consórcios entre grandes empresas parece ser compatível com a manutenção da competição nos leilões de blocos de petróleo e gás. ${ }^{19}$

Aditividade dos Valores dos Blocos Da seção 3 sabe-se que o valor dos blocos de petróleo podem não ser independentes. Em particular, se existem sinergias na exploração de blocos próximos, o valor de dois ou mais blocos sob a mesma propriedade tende a ser maior do que a soma dos valores individuais sob propriedades diferentes (superaditividade). Entretanto, parece não haver evidências a esse respeito para o caso brasileiro. Nas especificações adequadas para o contexto de valores comuns, a oferta de áreas na mesma bacia em uma determinada rodada (BLOCOS) não é importante para explicar o valor atribuído ao bloco. Na verdade, o coeficiente dessa variável se mostra negativo e não significativo nas especificações (C), (D) e (E). Ressalte-se que esse resultado pode estar condicionado ao método econométrico utilizado, que supõe independência entre os leilões e pode não estar capturando adequadamente as sinergias entre blocos próximos.

Outros Fatores Além disso, convém ressaltar alguns outros resultados importantes. Como esperado, blocos em águas profundas (PROFUNDA) recebem lances maiores do que em águas rasas (RASA), que por sua vez recebem lances superiores aos dos blocos localizados em terra. A título de ilustração, tomandose a especificação (D) como referência, tem-se que blocos em águas rasas recebem lances $426 \%$ maiores

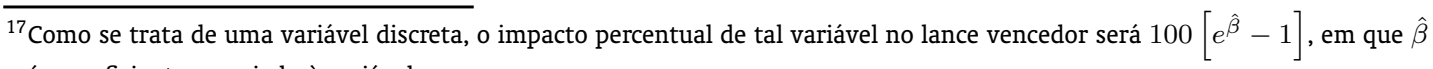
é o coeficiente associado à variável.

${ }^{18}$ Dos leilões em que participou a Petrobras ganhou $82 \%$ das vezes em terra, 95\% em águas rasas e $87 \%$ em águas profundas.

${ }^{19}$ Do ponto de vista estatístico, os lances ofertados por outros tipos de arranjos entre empresas não se mostraram significativamente diferentes entre si, nem de lances ofertados por uma única pequena atuando sozinha.
} 
do que os localizados em terra e que blocos em águas profundas recebem lances $143 \%$ superiores aos blocos em águas rasas Ressalte-se que esses valores não mudam muito para as outras especificações adequadas para o contexto de valor comum.

Note-se também que quanto maior a área do bloco (AREA), maior o lance recebido por ele: incremento de $1 \%$ na área do bloco gera aumento de $0,39 \%$ ou $0,40 \%$ no valor do lance vencedor, dependendo da especificação.

Por fim, aumentos no preço do petróleo no mercado internacional, na medida em que elevam o retorno sobre as reservas de hidrocarbonetos, resultam em lances maiores pelos blocos. Para cada $1 \%$ de incremento no preço do petróleo o lance vencedor é elevado em aproximadamente $0,85 \%$.

\section{CONCLUSÕES}

Este artigo investigou os determinantes dos lances vencedores em leilões de blocos de petróleo e gás no Brasil a partir da metodologia de Rezende (2008).Nesse sentido, o aumento da informação pública disponível aos participantes do leilão tem efeito positivo no valor dos lances. Trata-se de resultado esperado, pois a redução na dispersão das estimativas do valor do bloco tende a diminuir os efeitos negativos da "maldição do vencedor". Desse modo, em termos de arrecadação de receita, mostra-se acertada a estratégia de divulgar informações dos blocos licitados a todos os interessados antes dos leilões promovidos pela ANP.

Os resultados também indicam que, até quatro ou cinco participantes, o lance vencedor se eleva com o incremento do número de consórcios no leilão. A partir desse ponto o lance tende a se reduzir. Tratase de mais uma evidência de que os participantes levam em consideração a possibilidade de ocorrência da "maldição do vencedor" na definição de suas estratégias. Com poucos participantes o efeito do aumento da competição é dominante, elevando os lances. No entanto, um número muito grande de participantes aumenta a possibilidade de ocorrência da "maldição do vencedor", fazendo com que as empresas reduzam os lances para evitar que isso ocorra.

Ressalte-se que esse padrão somente é capturado quando a presença de assimetria de informação é corretamente levada em consideração. Desse modo, reforça-se o acerto na escolha de uma estratégia econométrica que, a despeito de sua simplicidade, permite a estimação estrutural dos parâmetros do modelo.

A propósito, por ser uma empresa mais bem informada que as demais, a participação da Petrobras, tende a elevar os lances vencedores. Nesse sentido, trata-se de evidência que contraria a previsão da teoria econômica. Condicional a toda informação pública disponível, os participantes informados tenderiam a ofertar lances menores (e não maiores). Entretanto, esse resultado deve ser encarado com reserva. Mais do que um fracasso da teoria, ele pode indicar que nem todo conjunto de informação pública disponível aos participantes é passível de ser capturado pelo modelo econométrico.

Ademais, parece não haver sinergias na exploração de blocos próximos entre si. Este resultado tem implicações importantes em termos do desenho dos leilões de blocos de petróleo e gás no Brasil. Na ausência de sinergias entre os valores dos blocos, as vantagens dos leilões abertos em termos de revelação da informação e, portanto, do aumento de receita, são dissipadas [Cramton (2007)]. O mesmo pode ser dito sobre leilões que permitem a oferta de lances distintos para diferentes pacotes de blocos. Sendo assim, embora haja espaço para melhora no desenho dos leilões promovidos pela ANP, o desempenho dos leilões selados de primeiro preço (sem a possibilidade de lances por pacotes de blocos) não tende a ser muito inferior às alternativas possíveis. ${ }^{20}$ Esta conclusão é reforçada quando se leva em conside-

\footnotetext{
${ }^{20}$ Para uma discussão mais detalhada sobre o desenho dos leilões de petróleo e gás no Brasil ver Ferriche (2009). Para uma análise dos resultados desses leilões ver Rodriguez et alii (2008).
} 
ração as vantagens desses leilões em termos de simplicidade e em termos de evitar colusão entre os participantes. ${ }^{21}$

Entretanto, é necessária cautela no uso dos resultados encontrados na avaliação do desenho dos leilões de petróleo e gás no Brasil. Embora permita a estimação estrutural dos parâmetros do modelo em um contexto de valores comuns, o método de Rezende (2008) não é capaz de tratar adequadamente algumas particularidades desses leilões, especialmente com relação à endogeneidade do número de participantes. Nesse sentido, este artigo deve ser encarado como uma primeira abordagem do tema. Desse modo, uma extensão natural é o uso de métodos mais sofisticados que levem em consideração as questões não tratadas pelo método de Rezende (2008) [ver Athey e Haile (2002) e Bajari e Hortacsu (2003), por exemplo].

\section{BIBLIOGRAFIA}

Athey, S. \& Haile, P. A. (2002). Identification of standard auction models. Econometrica, 70(6):2107-2140.

Bajari, P. \& Hortacsu, A. (2003). The winner's curse, reserve prices, and endogenous entry: Empirical insights from ebay auctions. RAND Journal of Economics, 34(2):329-355.

Brannman, L., Klein, J. D., \& Weiss, L. W. (1987). The price effects of increased competition in auction markets. Review of Economics and Statistics, 69(1):24-32.

Brasil, E. U. R. \& Postali, F. A. S. (2010). Informational rents in the Brazilian auctions for oil and gas. Working paper, Universidade de São Paulo.

Brasil, E. U. R., Postali, F. A. S., \& Madeira, G. A. (2008). Assimetrias entre competidores nos leilões de petróleo no Brasil. ANPEC, Anais do XXXVI Encontro Nacional de Economia.

Campo, S., Perrigne, I., \& Vuong, Q. (2003). Asymmetry in first-price auctions with affiliated private values. Journal of Applied Econometrics, 18(2):179-207.

Capen, E. C., Clapp, R. V., \& Campbell, W. M. (1971). Competitive bidding in high-risk situations. Journal of Petroleum Technology, 23(6):641-653.

Costa, A. R. \& Lopes, F. D. (2008). Participação de empresas estrangeiras e consórcios em leilões de blocos exploratórios de petróleo e gás no Brasil. Revista de Administração Contemporânea, 5(2):798-817.

Cramton, P. (2007). How best to auction oil rights. In Humphreys, M., Sachs, J., \& Stiglitz, J. E., editors, Escaping the Resource Curse, pages 114-151. Columbia University Press, New York.

Ferriche, R. C. (2009). Teoria de leilões com aplicação ao mercado de petróleo brasileiro. Dissertação de mestrado, Escola de Pós-Graduação em Economia, Fundação Getulio Vargas, Rio de Janeiro.

Furtado, R., Suslick, S. B., \& Rodriguez, M. R. (2008). A method to estimate block values through competitive bidding. AAPG Bulletin, 92(10):1293-1314.

Hendricks, K. \& Kovenock, D. (1989). Asymetric information, information externalities, and efficiency: The case of oil exploration. RAND Journal of Economics, 20(2):164-182.

Hendricks, K., Pinkse, J., \& Porter, R. H. (2003). Empirical implications of equilibrium bidding in fisrtprice, symetric, common value auctions. Review of Economic Studies, 70:115-145.

\footnotetext{
${ }^{21}$ Nesse sentido, não são encontradas evidências de que a formação de consórcios (principalmente entre grandes empresas) tem motivações anticompetitivas.
} 
Hendricks, K. \& Porter, R. H. (1992). Joint bidding in federal OCS auctions. AEA Papers and Procedings, 82(2):506-511.

Hendricks, K., Porter, R. H., \& Boudreau, B. (1987). Information, returns, and bidding behavior in OCS auctions: 1954-1969. Journal of Industrial Economics, 35(4):517-542.

Hendricks, K., Porter, R. H., \& Tan, G. (1993). Optimal selling strategies for oil and gas leases with an informed buyer. AEA Papers and Procedings, 83(2):234-239.

Hendricks, K., Porter, R. H., \& Tan, G. (2008). Bidding rings and the winner's curse. RAND Journal of Economics, 39(4):1018-1041.

Hendricks, K., Porter, R. H., \& Wilson, C. A. (1994). Auctions for oil gas leases with and informed bidder and a random reservation price. Econometrica, 62(6):1415-1444.

Hernandez-Perez, A. (2011a). Economics of oil regulation and the Brazilian reform: Some issues. Energy Policy, 39(1):57-65.

Hernandez-Perez, A. (2011b). Oil and gas bidding with a dominant incumbent: Evidence from the Brazilian oil block auctions. Texto para discussão, n. 12.

Hoffman, E., Marsden, J. R., \& Saidi, R. (1991). Are joint bidding and competitive common value markets compatible? Some evidence from offshore oil auctions. Journal of Environmental Economics and Management, 20(2):99-112.

Li, T. P. \& I., V. Q. (2000). Conditionally independent private information in OCS wildcat auctions. Journal of Econometrics, 98(1):129-161.

Matoso, R. \& Rezende, M. (2011). Asymmetric information in oil and gas lease auctions with a national company. Dissertação de mestrado, Disponível em: http://ssrn. com/abstract=1868976.

Matoso, R. S. (2009). Leilões de blocos exploratóno Brasil: Estudo do papel da petrobras. Dissertação de mestrado, IBMEC, Rio de Janeiro.

Mead, W. J., Moesidjord, A., \& Soerensen, P. E. (1986). Competition in outer shelf oil and gas lease auctions: A statistical analysis of winning bids. Natural Resources Journal, 26(1):95-111.

Menezes, F. M. (1994). Uma introdução à teoria de leilões. Revista de Econometria, 14(2):235-255.

Milgrom, P. P. \& Weber, R. J. (1982). A theory of auctions and competitive bidding. Econometrica, 50(5):1089-1122.

Motta, P. H. C. \& Ribeiro, E. P. (2010). Estimando o valor de blocos exploratórios de petróleo e gás natural: $\mathrm{O}$ caso dos leilões brasileiros. Anpec, Anais do XXXVIII Encontro Nacional de Economia.

Porter, R. H. (1995). The role of information in U.S. offshore oil and gas lease auctions. Econometrica, 63(1):1-27.

Rezende, L. (2008). Econometrics of auctions by least squares. Journal of Applied Econometrics, 23(7):925948.

Rodriguez, M. R., Colela Jr, O., \& Suslik, S. B. (2008). Os processos de licitação de áreas exploratórias e áreas inativas com acumulações marginais no Brasil. Revista Brasileira de Geociências, 38(2):63-79.

Thaler, R. H. (1988). The winner's curse. Journal of Economic Perspectives, 2(1):191-202. 